\title{
EDITORIAL
}

\section{Non-verbal communication and mental disorder ${ }^{1}$}

People with mental disorders are often found to be difficult to deal with; they are ineffective in social situations, become rejected and isolated, and feel anxious or otherwise uncomfortable in these situations. Bryant et al. (1976) found that $27 \%$ of a sample of neurotic out-patients were agreed to be socially inadequate; probably all psychotics can be regarded as socially inadequate; the same is true of at least $7 \%$ of the normal population. As Hooper et al. (1977) point out, "some of the most striking phenomena of what we call depression are only to be observed in the interaction and communication sphere', and the same is true of other syndromes.

Social inadequacy takes a variety of different forms; one kind consists of failure to establish and maintain friendly relationships, another consists of failure of assertiveness. In each case both verbal and non-verbal communication are involved, but we have found that non-verbal signals have a far greater impact than verbal ones for assertiveness (Argyle et al. 1972) and friendship (Argyle et al. 1970). Accordingly, recent developments in social skills training (SST) have placed a lot of emphasis on non-verbal communication (NVC). (There are a number of other ways in which social behaviour can fail - including lack of planning and initiation, failure to understand the rules or purpose of situations, failure to produce proper sequences of interaction.)

Text books of psychiatry provide clinical descriptions of syndromes which include a lot of information about NVC. Recent research, using more specialized techniques and careful experimental designs, has been able to add to this information at a number of points. Here are some examples.

Gaze. It has been confirmed that schizophrenics have a low level of gaze, when interviewed by psychologists about their problems; however, when talking either to patients or to strangers about impersonal matters their level of gaze is normal (Rutter, 1976).

Tone of voice. Research using a speech spectrometer, by Ostwald (1963) and others, has shown frequency distributions of the voices of different kinds of patients, such as the 'hollow voice' with few high frequencies found in brain-damaged patients and those with generalized fatigue. Other studies show that anxious people speak fast, and unevenly, with a breathy voice, and make of lot of speech errors (Scherer, 1974).

Spatial behaviour. Convicts and schizophrenics need a larger area of personal space than normals (Horowitz et al. 1969; Kinzel, 1970).

Patients also differ from normals in their perception of NVC. Williams (1974) found that schizophrenics were not upset by conflicting verbal-non-verbal signals, as the double-bind theory might suggest; schizophrenics were simply much less responsive than normals to NVC. Research in the repertory grid tradition suggests that one reason for this may be schizophrenics' lack of stable constructs for emotions and persons (e.g. Bannister \& Salmon, 1966). A number of studies have shown that delinquents are often inaccurate in the perception of approval and disapproval (McDavid \& Schroder, 1957). In our SST at Oxford we have found that socially inadequate neurotics often do not attend much to the social signals sent by others (Trower et al. 1978).

Our general approach has been to see social behaviour as a kind of social skill, in which there is constant modification of an actor's performance in the light of feedback (Argyle, 1969). Much of this feedback consists of NVC, e.g. from the other's face, and it is collected by looking in the right direction at the right time, the actor's glances constituting further NVC for the other (Argyle \& Cook, 1976). This model needs to be supplemented in a number of ways; for example, in any social situation there are rules governing what behaviour (including NVC) is appropriate, and there is a repertoire

1 Address for correspondence: Dr Michael Argyle, Department of Experimental Psychology, South Parks Road, Oxford OX1 3UD. 
of behaviour (including NVC) that is meaningful and appropriate in that situation, just as there are special moves in a game (Argyle, 1976).

Further understanding of the effects of failures of NVC can be gained by distinguishing between the different functions of NVC (Argyle, 1975).

\section{Communicating interpersonal attitudes}

As stated above, to signal to another person that you like them, and want to be friends, it is essential to send the right non-verbal signals, especially in the face and voice, but also via distance, orientation and posture. Neurotics who say they have no friends are often found to be either completely neutral in face and voice, or positively hostile. Similar considerations apply to establishing relations with the opposite sex, which requires the use of relevant NVC, including having an acceptable level of physical attractiveness - which can be to a large extent manipulated. Assertiveness or dominance similarly require the appropriate tone of voice, posture and facial expression.

In order to sustain any social encounter or relationship, it is necessary to be sufficiently rewarding. Schizophrenics have been described as 'socially bankrupt' in this respect (Longabaugh et al. 1966); depressives emit few rewards and are unable to elicit positive responses from others (Libet \& Lewinsohn, 1973).

\section{Communicating emotions}

Although it is useful to know the emotional states of others, cultural display rules prescribe how much shall be displayed on different occasions (Ekman et al. 1972). Mental patients seem to display too much of their anxiety, depression, etc., and this is disruptive. They also show considerable 'leakage' of what is not displayed to areas other than the face (Ekman \& Friesen, 1968).

\section{Supporting speech}

NVC supports speech in 3 ways: (a) completing and elaborating on verbal utterances; (b) providing evidence of attentiveness on the part of listeners, and giving immediate feedback (neurotic patients are often very unresponsive); $(c)$ managing the synchronizing of utterances. It has been reported that schizophrenics are bad at synchronizing; however, Rutter (1977) found that schizophrenics were no worse than hospitalized controls, when talking to patients or normals, in respect of double talking and silences.

\section{Self-presentation}

This is an important part of social behaviour. It is performed mainly by clothes and other aspects of appearance, and by voice and general style of behaviour. Schizophrenics do it too little, hysterics too much, paranoids present a bogus self-image, neurotics sometimes present an inappropriate one. Delinquents can be helped by getting rid of the scars and tattoo marks which once proclaimed their identity (Kurtzberg et al. 1968).

The origins of some of these deviations in NVC have been studied. Some, like facial expressions, are largely innate, though people still learn when to use them. Others, like gestures, are learnt from parents and other socialization agents in the culture. Skilled social behaviour is acquired by imitation of models, and trial and error, helped by verbal feedback from family and friends. Everyday social skills, the verbal-non-verbal system of conversation, and telephone skills, are acquired in this way. Individual variations in NVC may be due to imitating deviate models, lack of experience, or experience in a different culture or sub-culture. Individual forms of NVC may also be interpreted as symbolic means of communication, used when other methods have failed. Some psychoanalysts have interpreted bodily posture in this way: folded arms, self-wrapping, is seen as self-protection, especially of the breasts of women; a drooping, listless posture is seen as helplessness, a request for help (e.g. Mahl, 1968). Self-touching gestures on the other hand have been interpreted as a kind of 
non-verbal talking to oneself, e.g. to punish, or to give reassurance (Ekman \& Friesen, 1969). It is reported that during psychoanalysis a woman may take her wedding ring off, and several minutes later complain about her husband, when the idea has penetrated to consciousness. There has been little experimental support, however, for these interpretations.

Research on NVC in mental patients has already contributed to therapy. In the first place, careful study of a patient's NVC can help in diagnosis - his facial expression, voice, appearance, and so on. It follows that the psychologist must be able to see the patient - the Freudian position is not at all satisfactory for this. When a patient has a deviant pattern of NVC, this can be corrected fairly easily. Facial expression can be trained by means of a mirror, or by the help of a video tape recorder; the same is true of gestures and posture. Voice can be trained with an audio tape recorder. Appearance can be changed by advice about clothes and hair. Inaccurate perception of facial expression can be improved by training on photographs, like those in Ekman \& Friesen (1975). Recognition of tones of voice can be rapidly improved by listening to tape recordings of neutral messages spoken in different ways (Davitz, 1964).

There are two alternative views about all this. One is the theory that inadequate social behaviour is due to anxiety rather than to any lack of skills. This is supported by the finding that social performance is improved by desensitization and relaxation, though not so much as by SST (Wright, 1976; Marshall et al. 1977; Weinman et al. 1972). The psychoanalytic view is that failures of social performance are motivated perhaps by fear of, or hostility towards, people. On this theory SST should not improve either social behaviour or clinical condition. There is clear evidence that SST, placing particular emphasis on NVC, produces not only improved social behaviour, but also cure or marked improvement in socially inadequate neurotics. SST also improves the NVC of psychotics, and increases their subjective feelings of comfort (Goldstein, 1973), but has rather limited effects on clinical symptoms or in dealing with real-life problems (Trower et al. 1978; Hersen \& Bellack, 1976).

MICHAEL ARGYLE

\section{REFERENCES}

Argyle, M. (1969). Social Interaction. Methuen: London. Argyle, M. (1975). Bodily Communication. Methuen: London. Argyle, M. (1976). Personality and social behaviour. In Personality (ed. R. Harré), pp. 145-188. Blackwells: Oxford.

Argyle, M. \& Cook, M. (1976). Gaze and Mutual Gaze. Cambridge University Press: London.

Argyle, M., Salter, V., Nicholson, H., Williams, M. \& Burgess, P. (1970). The communication of inferior and superior attitudes by verbal and non-verbal signals. British Journal of Social and Clinical Psychology 9, 221-231.

Argyle, M., Alkema, F. \& Gilmour, R. (1972). The communication of friendly and hostile attitudes by verbal and non-verbal signals. European Journal of Social Psychology 1, 385-402.

Bannister, D. \& Salmon, P. (1966). Schizophrenic thought disorder: specific or diffuse. British Journal of Medical Psychology 39, 215-219.

Bryant, B. M., Trower, P. E., Yardley, K., Urbieta, H. \& Letemendia, F. (1976). A survey of social inadequacy among psychiatric outpatients. Psychological Medicine 6, 101-112.

Davitz, J. R. (1964). The Communication of Emotional Meaning. McGraw-Hill: New York.

Ekman, P. \& Friesen, W. V. (1968). Nonverbal behavior in psychotherapy research. Research in Psychotherapy 3, 179 216.

Ekman, P. \& Friesen, W. V. (1969). The repertoire of nonverbal behavior: categories, origins, usage and coding. Semiotica 1, 49-98.

Ekman, P. \& Friesen, W. V. (1975). Unmasking the Face. Prentice-Hall: Englewood Cliffs, N.J.
Ekman, P., Friesen, W. V. \& Ellsworth, P. (1972). Emotions in the Human Face. Pergamon: New York.

Goldstein, A. J. (1973). Structured Learning Therapy: Toward a Psychotherapy for the Poor. Academic Press: New York.

Hersen, M. \& Bellack, A. S. (1976). Social skills training for chronic psychiatric patients: rationale, research findings, and future directions. Comprehensive Psychiatry 17, 559580.

Hooper, D., Roberts, J. F., Hinchcliffe, M. K. \& Vaughan, P. W. (1977). The melancholy marriage: an enquiry into the interaction of depression. British Journal of Medical Psychology 50, 113-124.

Horowitz, M. J., Duff, D. F. \& Stratton, L. O. (1969). Body buffer zone. Archives of General Psychiatry 11, 651-656.

Kinzel, A. F. (1970). Body-buffer zones in violent prisoners. American Journal of Psychiatry 127, 59-64.

Kurtzberg, R. L., Safar, H. \& Cavior, N. (1968). Surgical and social rehabilitation of adult offenders. Proceedings of the Seventy-Sixth Annual Convention of the American Psychological Association 3, 649-650.

Libet, J. \& Lewinsohn, P. M. (1973). Concept of social skill with special reference to the behaviour of depressed persons. Journal of Consulting and Clinical Psychology, 40, 304-312.

Longabaugh, R., Eldred, S. H., Bell, N. W. \& Sherman, L. J. (1966). The interactional world of the chronic schizophrenic patient. Psychiatry 29, 78-99.

Mahl, G. F. (1968). Gestures and body movements in interviews. Research in Psychotherapy 3, 295-346.

Marshall, W. C., Stoian, M. \& Andrews, W. R. (1977). Skills training and self-administered desensitization in the reduction of public speaking anxiety. Behaviour Research and Therapy 15, 115-117. 
McDavid, J., \& Schroder. H. M. (1957). The interpretation of approval and disapproval by delinquent and non-delinquent adolescents. Journal of Personality 25, 539-549.

Ostwald, P. F. (1963). Soundmaking. Charles C. Thomas: Springfield, Ill.

Rutter, D. R. (1976). Visual interaction in recently admitted and chronic long-stay schizophrenic patients. British Journal of Social and Clinical Psychology 15, 295-303.

Rutter, D. R. (1977). Speech patterning in recently admitted and chronic long-stay schizophrenic patients. British Journal of Social and Clinical Psychology 16, 47-55.

Scherer, K. R. (1974). Acoustic concomitants of emotional dimensions: judging effect from synthesized tone sequences.
In Nonverbal Communication (ed. S. Weitz), pp. 105-111. Oxford University Press: New York.

Trower, P., Bryant, B. \& Argyle, M. (1978). Social Skills and Mental Health. Methuen: London.

Weinman, B., Gelbart, P., Wallace, M. \& Post, M. (1972). Inducing assertive behavior in chronic schizophrenics: a comparison of socio-environmental, desensitization, and relaxation therapies. Journal of Consulting and Clinical Psychology 39, 246-252.

Williams, E. (1974). An analysis of gaze in schizophrenics. British Journal of Social and Clinical Psychology 13, 1-8. Wright, J. C. (1976). A comparison of systematic desensitization and social skill acquisition with modification of a social fear. Behaviour Therapy 7, 205-210. 